\title{
LAS FUENTES LITERARIAS CASTELLANAS DEL GLOSADOR DE CELESTINA
}

\author{
Michel Garcia \\ Université de la Sorbonne Nouvelle (Paris III)
}

El glosador de Celestina utiliza menos fuentes directas de las que parece, porque la mayor parte de las citas que hace provienen de las fuentes reales - en número limitado - a las que recurre. Caso aparte constituyen las citas sacadas de obras recientes $y$, entre ellas, de obras castellanas, en la medida en que éstas no han dado lugar aún, cuando el glosador redacta su comentario, a una explotación sistemática. En el presente trabajo, intentaré inventariar esas obras y analizar el uso que el glosador hace de ellas. ${ }^{1}$

\section{Inventario.}

Las fuentes literarias castellanas citadas por el glosador de Celestina son las siguientes (entre paréntesis, se indica el número de citas efectivas):

Juan de Mena: Trescientas (62); La Coronación (7) Jorge Manrique: Coplas a la muerte de su padre (2) Bartolomé Torres Naharro: Epistolas (2); Comedias (3) Boscán: Poesias (3) Alexo Venegas: Agonia del tránsito de la muerte (1) Pedro Mexía: Silva de varia lección (8)

1 Se excluyen de este trabajo otras obras castellanas que no sean las "literarias", así como las jurídicas, históricas o médicas. 
Se observa una gran disparidad en el uso de unas y otras. Sólo las Trescientas se asemejan a una verdadera fuente para la glosa, quedando las demás limitadas a referencias episódicas.

Obras de Juan de Mena.

Las Trescientas. ${ }^{2}$

Distribución de las citas: Aparecen a lo largo de toda la obra, si bien con algunas variaciones: Auto I, 12 citas; II, 4 ; III, $5 ; \mathrm{IV}, 11 ; \mathrm{V}, 3$; VI, 4; VII, 1; VIII, 4; IX, 4; X, 1; XII, 1; XIV, 2; XV, 2; XVI, 3; XX, 2; XXI, 3.

Algunas coplas resultan más citadas que otras: la 110, 6 veces; la 116 , 3; la 241, 2; la 102, 2; y la 120, 2. Pero, en conjunto, lo que llama la atención es el gran número de coplas distintas que han sido citadas. Además, las referencias al Laberinto no respetan series a lo largo del comentario, salvo el caso excepcional de aquéllas que corresponden a varias coplas seguidas que tratan el mismo tema o un tema parecido : coplas 105, 106 y 110 (Auto II). Al contrario, el comentarista recurre a tal o cual copla sólo en función del texto de Celestina.

En el manuscrito, la disposición del texto de Rojas y de las glosas correspondientes permite diferenciar las distintas intervenciones del glosador: breves;

(a) al margen del texto de Celestina figuran algunas anotaciones

(b) la glosa propiamente dicha sigue el fragmento de la obra de Rojas a la que corresponde;

(c) dentro de esta glosa, se han incorporado anotaciones interlineales o marginales, que denotan un añadido a la glosa primitiva. ${ }^{3}$

Resulta interesante saber a qué clase de glosa corresponden las referencias a la obra de Mena.

${ }^{2}$ Las Trescientas y sus glosas. Cito a partir de Mena, Juan de, Las CCC del famosissimo poeta juan de Mena : con otras XXiiij coplas y su glosa y la Coronacion del mesmo poeta : e otras cartas : e coplas e canciones. Agora nuevamente añadidas. Sevilla : por Jacobo Crõberger alemã, año de mil e quinientos e diezisiete a veynte e quatro de setiembre [1517].

${ }^{3}$ Se incluye al final de este trabajo una lista de las referencias. 
(a) Notas marginales al texto de Celestina : $12^{4}$

(b) Dentro de la glosa : $17^{5}$

(c) Notas añadidas a la glosa : $33^{6}$

Las proporciones relativas de los tres tipos indican algunas tendencias. La glosa propiamente dicha resulta minoritaria : apenas más de la mitad de las añadidas y bastante menos si a éstas sumamos las que van al margen del texto a las que se las puede equiparar. La desproporción es sorprendente y deberá explicarse de algún modo. Las cifras favorecen a las anotaciones de tipo (c), dejando entrever - dado que éstas han sido incluídas posteriormente a la redacción de la glosa propiamente dicha - un cambio de perspectiva en la consideración por el glosador de las Trecientas como fuente posible de comentario.

La distribución presenta ciertas variaciones entre los distintos modos de glosa. Las notas al texto no van más allá del auto IX, mientras que las otras dos clases cubren la totalidad de la obra. Estas presentan también ciertas diferencias entre sí : los autos VI y XII merecen mención en la glosa, pero no en las notas añadidas; en cambio éstas aparecen añadidas al comentario de los autos IX, X, XIV y XX, que no van mencionados en la glosa.

Estas constataciones, al individualizar el estatuto de cada tipo de anotación, permiten conocer algo mejor el modo de trabajar del comentarista. Para los nueve primeros autos, los tres tipos de anotaciones se utilizan al mismo tiempo, si bien su frecuencia va creciendo de (a) a (c). Las anotaciones directas al texto se interrumpen súbitamente después del auto IX, sin que se observe un aumento de las demás clases. Al contrario, la no mención de las Trecientas en varios autos así como el escaso número de referencias en (b) y (c), en la medida en que suponen una relativa desafección del comentarista hacia esa obra, van en el mismo sentido. Pero la explicación principal reside probablemente en el contenido mismo de la obra, el cual, en algún momento de su desarrollo, no se presta tanto como al principio a un comentario inspirado de la obra de Mena. Con todo, no cabe la menor duda de que el glosador parece

\footnotetext{
${ }^{4}$ Auto I, 2; II, 1; III, 2; IV, 2; VI, 2; VII, 1;VIII, 1; IX, 1.

${ }^{5}$ Auto I, 4; II, 1; III, 1; IV, 3; V, 1; VI, 2; VIII, 1; XII, 1; XV, 1; XVI, 1; XXI, 1.

${ }^{6}$ Auto I, 6; II, 2; III, 2; IV, 6; V, 2; VIII, 2; IX, 3; X, 1; XIV, 2; XV, 1;XVI, 2; XX,
} $2 ; \mathrm{XXI}, 2$. 
haber explotado sistemáticamente las Trecientas con vistas al comentario de Celestina.

\section{Las distintas clases de citas.}

La terminología utilizada por el comentarista permite distinguir tres tipos de referencias a las Trescientas:

(a) la copla propiamente dicha;

(b) las "glosas de Juan de Mena ",

(c) " el glosador de las 300 " o " la glosa en las 300 » que remite probablemente a Hernán Núñez.'

Las referencias únicamente a las coplas (a) son escasas, 5 en total: dos de ellas figuran en la glosa, las otras tres han sido añadidas a ésta. ${ }^{8}$ Las referencias a las glosas de Juan de Mena, algunas veces asociadas con la mención de la copla correspondiente, son $46 .^{9} \quad$ Las referencias al glosador son $12 .^{10}$

Las " glosas de Juan de Mena " son notablemente más numerosas que las demás. Si se suman éstas a las del glosador, son 59 de las 64 en total. Se impone, pues, una conclusión : lo que interesa al comentarista no son las Trecientas sino sus glosas.

Esa designación distintiva de las referencias así como el uso particular que se hace de cada una de ellas, especialmente notable por lo que se refiere a las atribuidas al "glosador", incitan a considerar que se trata de fuentes distintas: unas se deberían al propio Juan de Mena, otras

${ }^{7}$ En algunos casos, el comentarista remite a la vez a la copla y a su glosa, probablemente de las atribuidas a Juan de Mena, con una fórmula del tipo «Juan de Mena en la copla $x$ et ibi glosa».

${ }^{8}$ A continuación se indican con $\mathrm{T}$ las anotaciones al margen del texto de Celestina (a); sin marca especial las incluídas en las glosa propiamente dicha (b); y entre corchetes [ ] las citas añadidas (c). referencias a las coplas: [II,13]; [II,13]; IV,24; V,3; [VIIa].

${ }^{9}$ Coplas y glosas : [I,85]; [I,85]; [I,122]; [IT]; [IIIT].

Sólo glosas : [I,123]; [I,125]; [I,162]; [IT]; [IIT]; [III,15]; [III,24]; [III,28]; [IIIT]; [IV,6]; [IV,7]; [IV,24]; [IV,24]; [IV,45]; [IV,60]; [IVT]; [IVT]; [V,7]; [V,12]; VI,10; VI,10; [VIT]; [VIT]; [VIII,16]; [VII,20]; [VIIT]; [IX,28]; [IX,28]; [IX,28]; [IXT]; [X,3]; [XIV,27]; [XIV,34]; XV,7; [XV,9]; [XVI,18]; [XVI,19]; [XX,2]; [XXT]; [XXI,13]; $[X X I, 17]$.

${ }^{10} \mathrm{I}, 22 ; \mathrm{I}, 123 ; \mathrm{I}, 125 ; \mathrm{I}, 126 ; \mathrm{II}, 13 ; \mathrm{IV}, 68 ; \mathrm{IV}, 68 ; \mathrm{V}, 12 ; \mathrm{VIII}, 21 ; \mathrm{XII}, 1 ; \mathrm{XVI}, 17 ; \mathrm{XXI}, 6$. 
a Hernán Núñez. Aclarar este punto resulta esencial, aunque sólo sea por la desproporción existente entre las dos clases. En efecto, resultaría inaudito que Mena, comentarista muy ocasional de su obra, sobrepasara al Comendador Griego, comentarista reconocido de la misma. Como se sabe, Mena comentó él mismo su poema de La Coronación del Marqués de Santillana, pero nadie - que se sepa - ha pretendido que hiciera lo mismo con las Trescientas. Sin embargo, la fórmula "glosa de Juan de Mena" puede alcanzar una apariencia de verosimilitud a la lectura de las glosas de la versión contenida en el Ms Esp. 229 de la Bibliothèque Nationale de París, generalmente distintas de las de Hernán Núñez, en las que se vislumbran ciertos atisbos de autodesignación. ${ }^{11}$ Sin entrar más adelante en un tema que sobrepasa con mucho los límites de este pequeño trabajo, lo único que cabe decir aquí es que el glosador de Celestina en ningún momento se refiere a las supuestas glosas de Juan de Mena del Ms Esp. 229, aún en los casos en que su comentario no coincide exactamente con la fuente que pretende manejar. ${ }^{12}$ Por lo tanto, por lo respecta a la fuente, las dos formulaciones - "glosa de Juan de Mena" y uel glosador de las 300» - son equivalentes, ya que las dos remiten a las glosas de Hernán Núñez.

Sin embargo, cada fórmula sigue un criterio diferente de aparición. Las referencias al glosador se incluyen todas, sin excepción, a la glosa propiamente dicha. El comentarista no añade ninguna mención de este tipo a las glosas ulteriores. En cambio, la casi totalidad de las referencias a las "glosas de Juan de Mena" figuran en las anotaciones añadidas (38 de un total de 42). Estas consideraciones nos llevan a pensar que el glosador varió de criterio para designar su fuente, sin que ésta cambiara realmente de naturaleza, entre una primera fase de su comentario, caracterizada por un ritmo reposado que autorizaba cierta

11 Glosa al verso 123b : "Yliadas esta yliada de Omero oue traduzido o romançado para el señor Rey donde largamente fable de la su vida por ende pues que alla fable aqui non fago minçion». Sobre esa versión, véase Maxim P.A.M. KERKHOF, "El Ms. 229 (PN7) de la Bibliothèque Nationale de París, base de las ediciones modernas del Laberinto de Fortuna de Juan de Mena," Medievalia. Instituto de investigaciones filológicas. Universidad de México, $\mathrm{n}^{\circ} 14$ (agosto 1993); también la memoria de literatura inédita de Stéphane GAUDION, Les gloses aux "Trescientas" ou "El Laberinto de Fortuna" de Juan de Mena : le Ms. Esp. 229 de la Bibliothèque Nationale de París. Mémoire pour la Maîtrise d'Espagnol. Paris III, 1995. La cita que inaugura esta nota corresponde a la pág. 61 de esta Memoria. Esa versión contiene algunas glosas de Hernán Núñez que fueron añadidas en última instancia por un lector de la misma.

${ }^{12}$ Glosas IIT, IIT, IV,24, IV,45, etc. 
elaboración estilística, y la(s) fase(s) posterior(es), marcada(s) por una forma de premura que hacía poco caso de la forma. Fue sin duda a raíz de ese cambio de perspectiva cuando el manuscrito se transformó de ejemplar dispuesto para la imprenta a un mero borrador, tal como se presenta hoy.

Contenido de las glosas.

El comentarista recurre a las Trecientas y a su glosa cuando Celestina toca algunos temas determinados. El mayor número de citas - 19 en total - concierne la mitología y la historia griegas y latinas. Luego viene la historia natural o prodigiosa, con 6 referencias. La hechicería da lugar a 4 citas. Por fin, entre los conceptos mencionados, generalmente con cita de filósofos antiguos o juristas, ocupan un lugar destacado la fortuna y la mujer: 4 en total. ${ }^{13}$

Los comentarios incluídos en las glosas se adecuan claramente a la glosa correspondiente de las Trecientas. Apenas si se nota algún detalle no mencionado por Hernán Núñez, lo que puede atribuirse al propio glosador o a una fuente secundaria que no ha tenido a bien citar. ${ }^{14} \mathrm{La}$ amplitud de las citas en la glosa primitiva facilita la comparación con la fuente. En cambio, las menciones añadidas despiertan algunas dudas al respecto, hasta provocar cierta perplejidad.$^{15}$ La causa, sin duda, reside en su formulación lapidaria, que no permite siempre identificar claramente el objeto al que se aplica la misma.

${ }^{13}$ Mitología e historia antigua : I,22; III,15; III,28; IIIT; IV,60; IV,68; VI,10; VIII,16; VIII,20; VIII,21; XIV,27; XIV,34; X,3; XVI,17; XVI,18; XVI,19;XXI,6; XXI,13; XXI,17. Historia natural y sobrenatural : I,125; III,24; IV,6; IV,45; V,3; XXT. Hechicería : I,122; I,123; I,126; IT. Fortuna : I,85; IX,28. La mujer : X,3; XV,9.

${ }^{14}$ Así, en I,22, éste afirma que Nero «mando poner a las dos partes de Roma fuego ...", hecho no mencionado por el Comendador griego.

${ }^{15}$ Aquí citaré sólo tres ejemplos. En las dos anotaciones añadidas en II,13, el comentarista remite a la glosa de Hernán Núñez cuando, en realidad, debiera hacerlo a las coplas de Juan de Mena, en las que expresa Macías. En IV,45, el comentarista escribe, a propósito de una propiedad del perro [Que ansi passa como aqui dize. Vi tu circa hoc glosa de Juan de Mena en la copla 244]. Nada parecido dice aquella glosa. Tampoco se entiende muy bien por qué el comentarista se refiere, en IIT, a la copla 93, en la que no se hace una mención particular de la fidelidad. 
Pero la razón esencial de la difícil interpretación de esas anotaciones breves consiste en que el comentarista no se refiere siempre al tema principal de la glosa que utiliza sino a aspectos muy secundarios de la misma. En la copla 78 y su glosa, la envidia sólo se cita de pasada; sin embargo, a ella se refiere únicamente el comentarista. La alusión a los cisnes (caistros) en la copla 170 no concierne en nada su voz, por ronca que sea; sin embargo, el comentarista la menciona.

Estas aparentes deficiencias no son tales sino más bien la manifestación de una forma de comentario particular. En las glosas, las citas del glosador sirven par explicar el texto de Celestina o para enriquecer el conocimiento del lector sobre un punto preciso, al remitirlo a una fuente nueva. El elucidar la obra de Rojas resulta ser el objeto principal del comentario. En cambio, cuando el comentarista va añadiendo sus anotaciones, Celestina ya sólo es un pretexto a comentario. La menor alusión justifica una llamada, en función del humor del comentarista, de sus intereses del momento o, simplemente, para hacer alarde de su erudición. En este caso, no hace más que atenerse a la práctica de sus modelos más imitados, como Chasseneux o Tiraqueau. ${ }^{16}$

\section{La Coronación.}

Las siete referencias que el comentarista hace a La Coronación del Marqués de Santillana conciernen únicamente las glosas redactadas por el mismo Mena. A continuación doy la lista correspondiente:

a) copla 16: No es cosa más propia del que ama etc. (III, 2)

b) copla 8: Litigioso caos (III, 27)

c) copla 7: Bolantes Harpias (III, 28)

d) copla 6: E dite (IV, 9)

e) copla 6: Gentil narciso (IV, 64)

f) copla 16: No alabarán a Orfeo (IV, 68)

g) copla 22: Ya resciben las venas, etc (VI, 6).

h) copla 16: No es cosa más propia del que ama etc. (III, 2)

Se observa una fuerte concentración de las citas en los primeros autos $\mathrm{y}$, más precisamente, en un número limitado de pasajes de los autos III y IV. Por otra parte, las coplas 6 y 16 son objeto de varias menciones. Estos hechos suponen una lectura selectiva de las glosas de

${ }^{16}$ Barthélémy Chasseneux, Catalogus gloriæ mundi; Consuetudines Burgundiæ. André Tiraqueau, De legibus connubialibus. Entre las fuentes recientes, son las más citadas. 
Mena por el glosador de Celestina, muy distinta de la que hizo de las Trecientas.

Pertenecen a la glosa primitiva las citas $b, d$ y $h$; las demás, a las glosas añadidas. Aún en el caso de las incluidas en el primer comentario, sólo d menciona con cierta amplitud la glosa de Mena; en b y h el comentarista se limita a remitir a ella con una fórmula semejante a ésta: "Vide hoc Juan de Mena en las coplas que hizo de la Coronación et ibi glosa, copla $22 . "$

Con todo, el comentarista toma muy en serio la glosa de Mena, por cuanto ésta responde a todos los criterios del género, a saber, la explicación literal y metáforica de los hechos mencionados, con gran acopio de citas de autores antiguos. De algún modo, el comentarista de Celestina disponía, con Mena, de un modelo de glosador castellano. Hasta cierto punto, no hay que descartar la posibilidad de que haya querido imitarlo en su propia tarea. Esto explicaría la importancia, algo sorprendente, ocupada por el poeta cordobés en el comentario de Celestina. ${ }^{17}$

Las otras fuentes.

Muy distinto parece el criterio seguido por el comentarista para citar a los demás autores castellanos a los que recurre.

Jorge Manrique: De este poeta, menciona dos veces Las coplas a la muerte de su padre.

Que siendo ella biva. Mui natural cosa es como lo dize Tiraquelo en las Leyes Conubiales folio 47 que todo lo passado nos deleita e aplaze más que lo presente y siempre nos parecen las cosas passadas mejores que las presentes como agora aquí la Celestina. $Y$ ansí lo dize tanbién Don Jorge en una copla "como a nuestro parecer qualquier tiempo passado fue mejor." (III, 11)

Descubrenos la çelada etc. Estas palabras son conforme (sic) a las de don Jorge Manrrique a la muerte del Maestre de Santiago, su padre, que en una copla dize ansi hablando de el mundo y de esta vida: "Los plazeres

\footnotetext{
${ }^{17}$ De algún modo, Mena pudo desempeñar el papel de Petrarca, pero a lo castellano.
} 
e dulçores / de esta vida trabajada / que tenemos / ¿que son sino corredores / y la muerte es la çelada / en que caemos? No mirando a nuestro daño / corriemos a rrienda suelta / sin parar / desque vemos el engaño / y queremos dar la buelta / no ai lugar etc." Que, aunque en romançe, no ai obra tan subida e de tan galanas sentençias en su materia e proposito. (XXII, 9)

Si bien, en la primera glosa, el comentarista se limita a citar al poeta por la conformidad que encuentra entre tres de sus versos y un pasaje de Celestina, el juicio que añade al final de la segunda muestra claramente que lo que le lleva a citar a Manrique es el entusiasmo que provoca en él la lectura de su obra. La restricción - o petición de indulgencia hacia un lector erudito - expresada por la fórmula "aunque en romançe" pretende justificar una actitud poco habitual en la clase de empresa que lleva a cabo el glosador, el cual debería atenerse sólo a fuentes latinas. Pero, dado el uso que hace de otro poeta romance como es Juan de Mena, la justificación parece concernir más el desvío que supone prestar interés no ya a una fuente erudita, aunque fuera redactada en castellano, sino a una obra de creación. Por otra parte, tenemos aquí un buen testimonio de la fama que cobró tempranamente la obra de Jorge Manrique.

Bartolomé Torres Naharro. Este autor inaugura la corta lista de escritores modernos castellanos citados por el comentarista de Celestina. Con él, entramos en un campo donde resulta difícil moverse, por cuanto la motivación del glosador puede remitir, no tanto a un criterio objetivo, como a un criterio tan íntimo como el gusto personal. Por otra parte, la referencia a autores recientes contribuye a definir más precisamente las cultura del comentarista fuera del campo estrecho de su quehacer. ${ }^{18}$

\section{Epistolas}

Que quien junto en diversos etc. Estas son las palabras en effecto del capítulo diversis fallacijs con la glosa allí de cleri conjuga. Onde dize: "pluribus intentis minor est ad singula sensus et dum ad utrumque festinat neutrum bene perficit" [...] Y Torres Naharro en la epístola $2^{\mathrm{a}}$ dize ansí: mientra tu querer ordenes por tan muchas

${ }^{18}$ Sigo opinando que el comentarista de Celestina tenía una formación de jurista y que redactó su obra en un contexto universitario. 
opiniones porque en ninguna lo tienes quando en diversas lo pones. (I, 106; Epístola 2a , vv. 101-104)

Ni convalesce la planta. Esto tanbién como ya e dicho es de Séneca en la carta 2 pero estas palabras solas de por si las refiere Torres Naharro en una carta 2 onde dize [folio 45r]: si tu riqueza es tanta según a ti conviene que poco crece la planta traspuesta de cada día. ${ }^{19}$ (I, 151; Epístola 2, vv. 106-109)

\section{Comedias}

Pues a los padres y a los maestros. Estas son palabras del Philósopho en el libro 8 de las Ethicas capítulo [?] [...] Conmedia llamada Calamita dize lo mismo citando al Philósopho nuestro que a Dios, padre y maestro no se halla equivalencia. $(I, 177)$

Nunca mucho costo poco. Torres Naharro, en la comedia Aquilana, en la $1^{a}$ parte o jornada, dize estas palabras: que nunca mucho costó poco ni se dan perlas de balde. Y son palabras de Séneca en la charta 19, que escrive a Lucillo, que dize ansí: non potest parvo magna res constare. (VIII, 12)

En que mes cae Sancta Maria de agosto. Esta mesma pregunta pone Torres Naharro en una de sus comedias en la comedia que llama [en blanco]. ${ }^{20}$ (XIV, 14)

El glosador parece tener buen conocimiento de la producción de Torres Naharro, ya que sus citas abarcan obras de distinto género $y$, además, cada comedia citada lo es sólo una vez. Llama la atención cómo asocia a Torres Naharro con filosófos antiguos, ofreciendo así de su obra una visión erudita, sólo matizada por la última cita, que remite a la tradición del pastor bobo, más conforme con el carácter teatral y lúdico de las Comedias.

Boscán. A pesar de que Boscán figura en el Cancionero General de Hernando del Castillo, el comentarista no lo cita como poeta de la tradición

\footnotetext{
${ }^{19}$ Hay que leer : si tu riqueza no es tanta / según a ti convenia /.

${ }^{20}$ Se trata de la Comedia soldadesca, vv. 28-29.
} 
cancioneril, en la estela de Jorge Manrique, sino como portavoz de la nueva corriente poética, ya que las citas se refieren únicamente a sonetos, la forma moderna por antonomasia.

1, 94. Y Boscán agora nuevamente haze un soneto de este de alinde que encomiença: "alinde adonde vas etc". ${ }^{21}$

1, 102. Y Boscán en un soneto dize: "Quien dize que el absencia causa olvido merece ser de todos olvidado etc". O quando la absencia es pequeña y no grande y ansí lo podemos entender secundo modo. ${ }^{22}$

4, 12. Y ansí tanbién Boscán dize en un soneto: "quien dize que el absencia causa olvido, merece ser de todos olvidados [sic] etc." ${ }^{23}$

El comentarista se muestra atraído por la capacidad del poeta por renovar fórmulas avaladas por la tradición y su carácter eminentemente "moderno" ("agora nuevamente").

Alexo Vanegas. Ese autor merece una sola mención, incluida en una nota interlineal dedicada al Etna, dentro de una profusa glosa sobre volcanes. Más allá de esta referencia, por excepcional, anecdótica, el comentarista demuestra un evidente interés por las obras de erudición recientes, por más que haya afirmado su preferencia por las obras latinas.

Los sulfereos fuegos que los hervientes. [...] Y este monte Ethna se llama oi en día por otro nombre que se llama el monte Mongival como lo dize Polidoro De inventoribus rerum libro 6 capítulo 9 onde quenta tanbién de estos montes otras muchas cosas que por él se pueden ver. [Tanbién se llama este monte Valerii como lo dize Alexio Vanegas en el libro del Agonía del tránsito de la muerte capítulo 7 punto 6.]. (II, 24)

${ }^{21}$ lib. I, $n^{\circ} 20$. No es un soneto sino una quintilla: Alinde, en yr a do vas / tu propiedad desfallece.

22 lib. II, soneto LXXXV (I, 102)

${ }^{23}$ lib. II, soneto LXXXV (IV, 12) 
Pedro Mexía. La Silva de varia lección es la obra reciente que más cita el comentarista. Las siete citas se incluyen todas en la redacción primera de la glosa y son bastante más extensas que las que conciernen a otros autores. Por otra parte, están redactadas con un cuidado que demuestra la reverencia que sentía el glosador por esa fuente. Las fórmulas que justifican la inserción de esas citas, que indico en negrillas, hacen hincapié en el extenso tratamiento por Mexía - vale tanto como decir "erudito y documentado" - de los temas concernidos. En la quinta cita, no duda en colocar a su modelo por encima de todas las fuentes hasta entonces manejadas ("pone allí otra razón más verdadera").

Ser machos y hembras. Sylva de varia leción en la $1^{\mathrm{a}}$ parte capítulo 33 allegando a Plinio y a otros muchos authores dize esto mismo como es de la palma que es cierto que entre ellas ai unas machos y otras hembras y que en ellas se conoce esto mejor que en otros árboles algunos, porque las hembras dan el fructo de los dátiles $y$ los machos [folio 42r] solamente echan la flor $y$ quando vienen a dicha a cehar (?) dátiles no son de gusto ni por comer. (I, 139)

(Como los que careciendo). Esto puede dezir quí nuestro author por Mahoma, el cual inventó la malvada secta en la cual permitió muchos vicios y libertades y carnalidades y que uno pudiese tener muchas mujeres, por las quales le siguieron muchos más que por pensar ser cierta su doctrina como lo cuenta Sylva de varia lección 1 parte ca.13 onde largamente ${ }^{24}$ dize su principio el cual començó a sembrar su seta por el año del Señor de 640. (I, f. 53v)

Por muchas razones comprueva esto que no basta venir o descendir de padres nobles si cada uno por su persona no lo es. La Summa de vitiis et virtutibus 2 parte, Tractado De superbia capítulo 28, y aun Sylva de varia lección en la 2a parte capítulo 36 dize que todos los más linajes que ai nobles y antiguos sus principios fueron de hombres baxos que haziendo obras señaladas de virtud y fortaleza ganaron claro renombre. Por lo qual no ai razon que nadie se llame noble ni se estime en la nobleza de sus

${ }^{24}$ El subrayado en letras en negrilla de estas citas de la Silva es nuestro. 
antepassados como aqui dize el author si él mesmo por su persona no lo es. (II, 8 )

De la buena disposición de un hombre y estatura y qué cosas ayan de concurrir para que se pueda dezir ser bien dispuesto, dízelo muy largo Silva de varia leción en la $2^{\mathrm{a}}$ parte, cap. 19, onde se puede bien ver. (IV, 63)

es cierto que el cuerpo del hombre muerto sobre el agua anda la barriga hazia abaxo, y si es mujer, boca arriba porque es más honesto que ande boca arriba que no hazia abaxo. Tanbién dize lo mesmo Silva de varia leción, en la fol. 19, aunque como él allí dize, sea esto en sí verdad, pone allí otra razón más verdadera, de donde se cause y que no sea esto sólo para denotar la honestidad de la mujer. $(X, 3)^{25}$

Y quien tanbien aia sido el primero inventor de las campanas y a que nos avemos en algo alargado dizelo Sylva de varia leçion en la $2^{\mathrm{a}}$ parte capitulo 40 onde quenta el mucho provecho que se nos sigue del uso de ellas. (XII, 1)

El pie izquierdo adelante. Que sea la causa que todas vezes que un hombre quiere correr siempre vemos que echa el pie izquierdo delante como agora aqui este ; dizelo mui bien Silva de varia leçion en la 2a parte, capitulo 27, onde dize que es por en començar a correr con el pie derecho que con ello gana ventaja. Lo qual dize que es lo mismo en todos los demas actos y que es cosa mui natural de començar con el miembro derecho mas aina que con el izquierdo onde pone mui buenos exemplos [163 recto] de todo esto, porque en començando con el pie derecho llebasse aquella ventaja de aprovecharse mas del pues en effecto se manda mejor que no el izquierdo y porque, como dize el comentador de Aristotiles en Las Problemas 29 particula problema 12: "omnis motus sit in dextris et frelementum (?) in sinistris" ('que todo movimiento hazemos o començamos en la parte derecha pero el hincapie e sustentamiento hazemoslo en la parte (^simis) siniestra'). (XII, 12)

${ }^{25} 1^{\text {a }}$ parte, capítulo 16 . 
Lo demas de que hedad aia de ser el varon quando se aia de casar, y ansimesmo la mujer tractalo largamente Tiraquello en las Leyes conubiales, folio $51, n^{\circ} 31$, con los demas y romançe novissimamente en esta materia habla Sylva de varia leçion en la 2a parte, capitulo 14, onde singularmente por el se puede ver lo demas. (XVI, 9)

\section{Conclusión.}

La empresa del comentarista de Celestina pertenece a una tradición ya antigua en su día, que las nuevas corrientes culturales no habían hecho desaparecer. Por sorprendente que nos parezca la lectura que éste lleva a cabo de una obra - Celestina - en la que hemos dejado de ver una suma de citas y referencias acopiadas en alarde de erudición universitaria, su manera de actuar no rebaja nuestro interés por la obra de Rojas, sino que lo enriquece por medio de una contextualización que nos hubiera costado realizar sin el testimonio de lectores contemporáneos. Además, nos informa de cierta" evolución del gusto literario en un siglo que tuvo un papel tan esencial en la formación de una producción hispánica de alto vuelo. Esta se caracteriza por la permanencia de un bagaje heredado de los siglos anteriores junto con la afición por nuevas formas de escritura. Sin embargo, la tradición, aún renovada en la forma, parece vencer al deseo de innovación, como lo demuestra el entusiasmo que parece despertar en nuestro glosador la Silva de Mexía, ejemplo de una erudición farrogosa que dará tanto que decir, siglo y medio más tarde, al Padre Feijoo.

\section{Citas de las Trescientas ${ }^{26}$}

\section{Apéndice}

copla 10 de las añadidas: Mira Nero etc. $(I, 22)$

copla 224: Fortuna medianamente $(I, 85)$

copla 13 de las añadidas: id. $(I, 85)$

copla 241: Tenía huessos de coraçón $(\mathrm{I}, 122)$

copla 110: Tela de cavallo $(\mathrm{I}, 123)$

copla 110: id. $(\mathrm{I}, 123)$

copla 14: La piedra del nido del águila $(I, 125)$

${ }^{26}$ Se indica: el número de la copla referida; las palabras de Celestina que inician el pasaje comentado de la obra; entre paréntesis, la referencia al auto y a la nota correspendiente de la glosa. 
copla 241: id. $(1,125)$

copla 110: Coraçones de cera $(I, 126)$

copla 127: Mas los que mucho dessean $(\mathrm{I}, 162)$

copla 234: Que es necessaria turbación (IT)

copla 110: De cera llenos de agujos (IT)

copla 105: Aquel Macías (II,13)

copla 106: id. (II,13)

copla 110: id. (II,13)

copla 93: Señor, flaca es la fidelidad (IIT)

copla 131: Muertas sí cansadas no (III,15)

copla 53: Los sulfereos fuegos que los hervientes (III,24)

copla añadida 11: Bolantes Harpias (III,28)

copla 240: La fuerça de su acelerado principio (IIIT)

copla 246: Alecto (IIIT)

copla 164: Ni otras nocturnas $(I V, 6)$

copla 85: Pax sea en esta casa $(\mathrm{IV}, 7)$

copla 26: No hazen rico, sino ocupado (IV,24)

copla 19: id. (IV,24)

copla 80: id. (IV,24)

copla 244: El perro con todo su ímpetu (IV,45)

copla añadida 13: En franqueza Alexandre (IV,60)

copla 116: No alabarán a Orfeo (IV,68)

copla 120: id. (IV,68)

copla 116: En otra impressión dize (IVT)

copla 120: id. (IV ${ }^{\mathrm{r}}$ )

copla 110: No creyera en yervas $(V, 3)$

copla 54: La raleza de las cosas $(V, 7)$

copla 138: O que mala cosa es de conocer $(\mathrm{V}, 12)$

copla 130: Tusca Athelata (VI,10)

copla 252: id. (VI,10)

copla 221: Solo un poco de agua clara con un eburneo peyne(VIT)

copla 8: atrevimiento de un solo hombre gano a troya (VIT)

copla 112: simpleza es no querer amar i esperar de ser amado (VIIT)

copla 41: El gran poeta Ovidio (VIII,16)

copla 13: Aunque primero sean los cavallos (VIII,20)

copla 129: Apuleyo el veneno (VIII,21)

copla 9: Nunca venir plazer sin contraria çoçobra (VIITT)

copla 257: Ley es de fortuna (IX,28)

copla 267: id. (IX,28)

copla 2: id. (IX,28)

copla 154: la muerte temprana (IXT)

copla 73: Por qué fue tanbién a las hembras $(X, 3)$

copla 116: Da el relox (XII,1)

copla 114: Las leyes de Athenas (XIVT) 
copla 216: Mira a Torcato romano (XIV,34)

copla 223: Sacrílega hambre $(X V, 7)$

copla 121: Lo primero discreción, honestidad $(X V, 9)$

copla 102: Myrrha con su padre (XVI,17)

copla 5: Simiramis con su hijo (XVI,18)

copla 103: Canaçe con su hermano (XVI,19)

copla 78: Cata que la enbidia $(X X, 2)$

copla 170: Con mi ronca voz de cisne (XXT)

copla 102: Orestes a su madre Clitinestra $(X X I, 6)$

copla 130: Medea la nigromantesa (XXI,13)

copla 72: Cortaron las hadas (XXI,17)

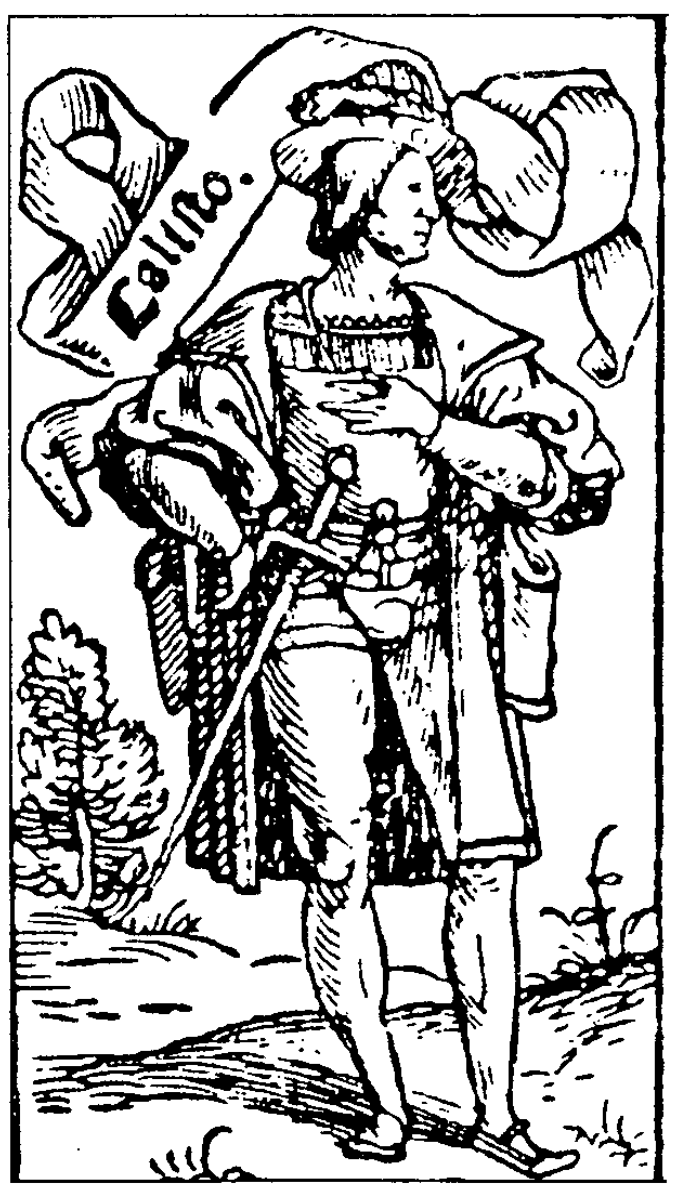

Célestine. Lyon 1529. 